https://doi.org/10.48009/2_iis_2005_154-160

\title{
AN EMPIRICAL ANALYSIS OF THE TECHNOLOGY CAMEL
}

\author{
Wallace A. Wood, Bryant University, wwood@bryant.edu \\ Suhong Li, Bryant University, sli@bryant.edu
}

\begin{abstract}
The new technology product adoption lifecycle (TALC) has been classified as including five groups: innovators, early adopters, early majority, late majority and laggards and is visualized as a bell curve. Ghaffari and McNurlin introduced a modification of this with their concept of the technology camel. They renamed the innovators to be Eager Beavers and the laggards to be Technically Averse and they posited that the technology camel was applicable for both individuals and organizations. The focus of this study was to investigate whether the technology camel is a good model for explaining the adoption of information technology. It was found that the adoption curve has shifted to the left, with fewer individuals/companies belonging to the technically adverse group. Moreover, the results showed that individuals are ahead of organizations in the adoption of new technologies and males are more willing to adopt new technologies than females. Possible explanations are given for the differences.
\end{abstract}

Keywords: technology adoption life cycle, technology camel, gender difference, survey methodology

\section{INTRODUCTION}

Bass [2] is viewed by many as the developer of the seminal model for new product adoption for consumer durables. His model was for new classes of products as opposed to new models of older products. He identified those individuals who adopt an innovation independent of others as innovators. This terminology was consistent with the literature at the time which classified adopters as (1) Innovators, (2) Early Adopters, (3) Early Majority, (4) Late Majority, and (5) Laggards based on the timing of the adoption. He defined Innovators as being the first $2.5 \%$ of the adopters and groups (2) thru (5) as imitators and assumed Innovators as not being influenced in their initial purchase of a new product while imitators are influenced by the number of previous buyers. Bass's model was "tested" on a variety of consumer durable goods at the time.

In a paper written 20 years later several of Bass's assumptions were challenged and several updates to his model were offered [6]. For example, the concept of communication between Innovators and imitators was introduced. The original model was for the market in the aggregate, but the authors reported on some research indicating that it can be applied to individuals. Other assumptions questioned include that the Bass model is a demand model and there is no provision for supply restrictions. This, coupled with the assumptions that it did not take into effect consumer expectations such as price; it failed to recognize the decreasing time between successive generations of new technologies; and it did not consider the "take-off" time for new products raised the question of its applicability to information technology in general. Despite these questions, research continues on this model and its derivations.

Moore [8] writes of the Technology Adoption Life cycle (TALC) as a means for classifying the market and its reaction to a new high technology product where the adoption over a period of 
time is viewed as a bell-curve (see Table 1 and Figure 1). Moving from left to right, one sixth of the curve is early market (innovators and visionaries), one third is the early majority, one third is the later majority, and one sixth is the laggards. Each group is identified by their relative acceptance of or aversion to technology and to risk. Among the five groups, innovators are technology enthusiasts, the first to try every cool new gadget and gizmo. Visionaries are eager to embrace new technologies to solve their problems and to gain competitive advantage, and will pay large amounts of money for new technologies that they believe will help solve their problems. The early majority are pragmatists who do not like the risk of pioneering, but are ready to see the advantages of tested technologies. People/organizations in the late majority are conservatives who only expect mature technology at commodity prices. The people /organizations in the laggard segment are skeptics and do not willingly engage or use technology products. They will buy technology only when it is buried so deep in a product that they do not know it is there. The difference between early market (innovators and visionaries) and the early majority groups is so great that the sale of the new product frequently falls into a chasm before recovering. Spanning this chasm of decreased sales and a loss of market share is vital to the longterm success of a new product and eventual market dominance [8].

Table 1. Percentage of each group in TALC and Technology Camel Model

\begin{tabular}{|c|c|c|}
\hline & $\begin{array}{c}\text { Traditional TALC by } \\
\text { Moore [8] }\end{array}$ & $\begin{array}{l}\text { Technology Camel defined by } \\
\text { Gahffari and McNurlin [3] }\end{array}$ \\
\hline Eager Beavers & $2.5 \%$ & $3.0 \%$ \\
\hline Early Adopters & $13.5 \%$ & $12.5 \%$ \\
\hline Early Majority & $34.0 \%$ & $32.5 \%$ \\
\hline Late Majority & $34.0 \%$ & $32.5 \%$ \\
\hline Technically Adverse & $16.0 \%$ & $19.5 \%$ \\
\hline Total & $100.0 \%$ & $100.0 \%$ \\
\hline
\end{tabular}

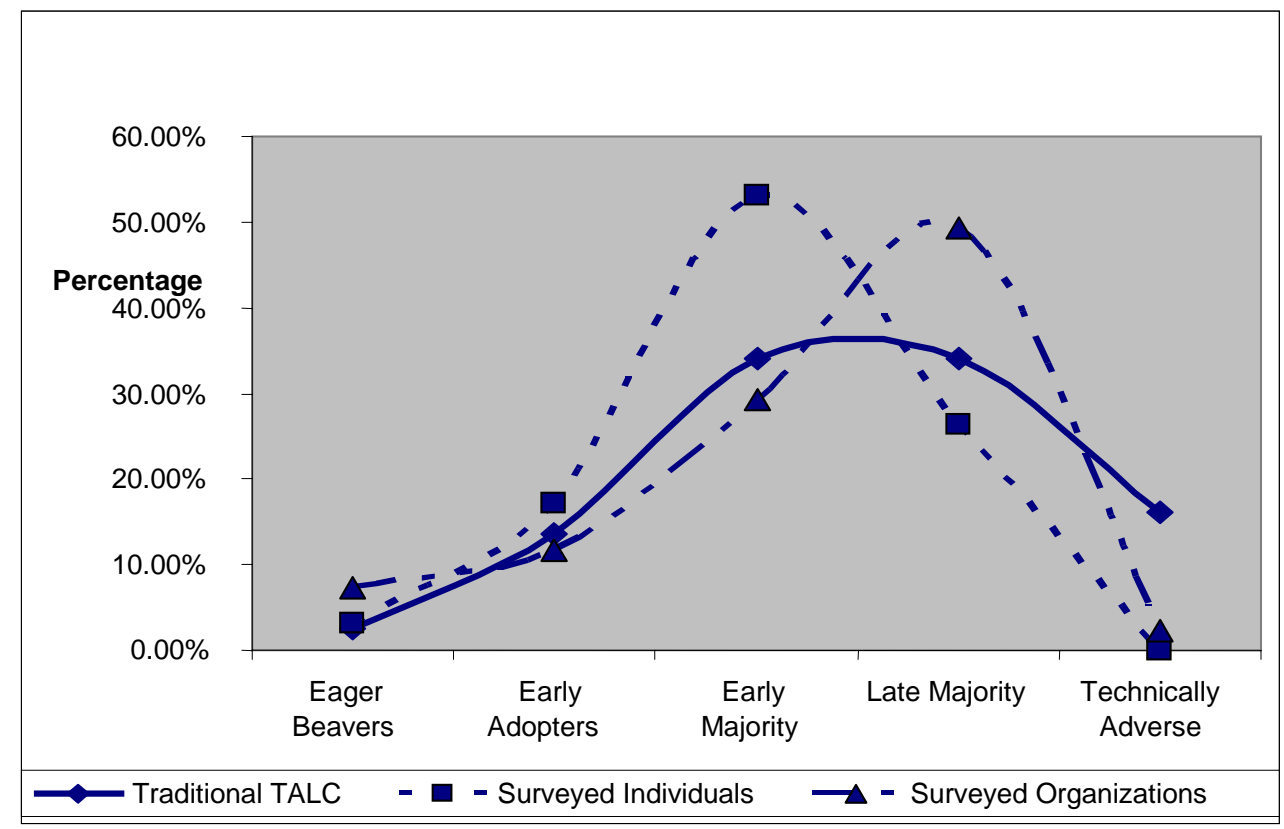

Figure 1. Technology Adoption Life Cycle 
Elizabeth Ghaffari and Barbara McNurlin [3] proposed the "Technology Camel" as an interesting way to describe the five clusters in the TALC (see Table 1 and Figure 2). According to them, these five clusters look a lot like a two-humped camel which is lying on its stomach with its nose inside a tent which represents a new technology such as the Web. The first cluster (Eager Beavers) is his nose as he nudges the flaps of the tent. The second (Early Adopters) is his slowly rising neck. The third (Early Majority) and fourth (Late Majority) are his two big humps. And the fifth cluster (Technically Averse) is his rump. They argue that this model holds well for business users, departments, companies, and industries as well as consumers. Because of this, they further argue that IS departments need to benchmark their customers, employees and business units against those groups and develop different strategies for assisting each group in utilizing new technology since each group has a different willingness and ability to adopt new technologies.

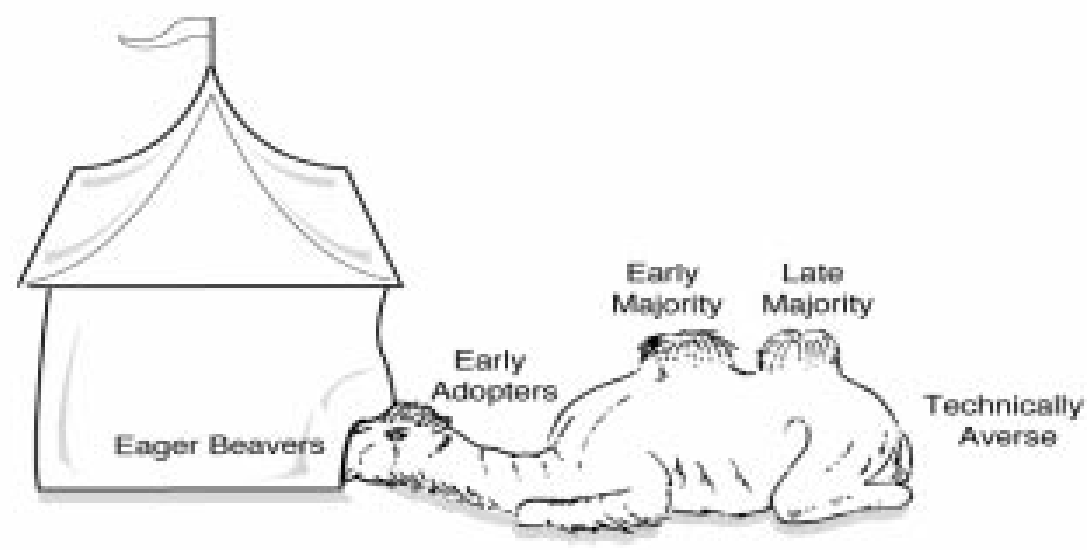

Source: Elizabeth Ghaffari and Barbara McNurlin, "The Technology Camel," unpublished paper.

Figure 2. The Technology Camel Model

On the other hand, many studies have pointed out that the adoption of a new technology is impacted by many factors, such as financial capability, attitude and past experience with new technologies, gender, senior management support, the inclusion of technology in corporate strategy, and perceived difficulty and perceived benefits of using the new technology $[1,5,7,9$, $10,11]$.

Compared with the many aforementioned factors, the technology camel represents a relatively simple model and explanation for the adoption of new technologies. The purpose of this study is to verify whether the concept of the technology camel holds true for both individuals and organizations. Specifically, the following questions were investigated:

1. Whether the TALC in the form of the technology camel holds true for individuals?

2. Whether the TALC in the form of the technology camel holds true for organizations?

3. Is there any difference between individuals and companies in relation to the technology camel model of technology adoption? 
4. Is there any difference between males and females in relation to the technology camel model of technology adoption?

\section{RESEARCH METHODOLGY}

The data for this study was collected from graduate students enrolled in introductory MBA and MSIS courses taught by one of the authors during the academic year 2003-2004. The students were first introduced to the concept of the technology camel and then were asked to identify the group they believed they were in and why. They were also asked to place their organization in one of the groups and to explain why. A total of 186 usable responses were collected. Of the sample, $61 \%$ were male and $39 \%$ were female.

\section{ANALYSIS AND DISCUSSION}

\section{Technology Camel Representing Individuals}

To test whether the percentage of the surveyed individuals in each group is the same as that of the technology camel model, a chi-square test of homogeneity was performed. The intent was to test the hypothesis that the percentage of the surveyed individuals in each group (eager beavers, early adopters, early majority, late majority and technology adverse) would not differ significantly from the corresponding percentage of each group defined in the technology camel model (3\% for eager beavers, $12.5 \%$ for early adopters, $32.5 \%$ for early majority, $32.5 \%$ for late majority and $19.5 \%$ for technology adverse). The results disproved the hypothesis, with significance level less than .001 (see Table 2). Compared to the technology camel model, about $5 \%$ and $21 \%$ more individuals are located in the early adopters and the early majority groups, respectively, and about $6 \%$ and $20 \%$ fewer individuals belong to the later majority group and technically adverse groups, respectively. Interestingly, none of the surveyed individuals classifies him/herself as being in the technically adverse group. When graphed on a chart, the technology camel representing the surveyed individuals would be a camel without a rump and having two unbalanced humps. His first hump is twice as high as the second one.

Table 2. Comparison of Technology Camel Model for Individuals/Organizations

\begin{tabular}{lcccc} 
& \multicolumn{2}{c}{ Surveyed Individuals } & \multicolumn{2}{c}{ Surveyed Organizations } \\
\cline { 2 - 5 } Group & $\begin{array}{c}\text { Actual } \\
\text { Freq. }\end{array}$ & $\begin{array}{c}\text { Expected } \\
\text { Freq. }\end{array}$ & $\begin{array}{c}\text { Actual } \\
\text { Freq. }\end{array}$ & $\begin{array}{c}\text { Expected } \\
\text { Freq. }\end{array}$ \\
\hline Eager Beavers & $6(3.2 \%)$ & $6(3.0 \%)$ & $13(7.3 \%)$ & $5(3.0 \%)$ \\
Early Adopters & $32(17.2 \%)$ & $23(12.5 \%)$ & $21(11.8 \%)$ & $22(12.5 \%)$ \\
Early Majority & $99(53.2 \%)$ & $60(32.5 \%)$ & $52(29.2 \%)$ & $57(32.5 \%)$ \\
Late Majority & $49(26.3 \%)$ & $60(32.5 \%)$ & $88(49.4 \%)$ & $57(32.5 \%)$ \\
Technically Adverse & $0(0.0 \%)$ & $36(19.5 \%)$ & $4(2.2 \%)$ & $34(19.5 \%)$ \\
Total & 186 & 186 & 178 & 178 \\
Chi-square Test & $\chi^{2}=65.90, \mathrm{df}=4, \mathrm{P}<0.001$ & $\chi^{2}=56.61, \mathrm{df}=4, \mathrm{P}<0.001$
\end{tabular}

Figure 1 shows that, when compared to the traditional TALC, the TALC for the surveyed individuals has shifted to the left and steepened. 


\section{Technology Camel Representing Organizations}

A chi-square test was again performed to see whether the percentage of the surveyed organizations in each group was comparable to the percentages of each group in the technology camel model. The results (see Table 2) disproved the hypothesis, with a significance level less than 0.01 . The results show that the technology adoption pattern for the surveyed organization is statistically different from that of the technology camel model. About 4\% and 17\% more organizations belong to the eager beavers and later majority groups, respectively. About $17 \%$ fewer organizations belong to the technically adverse group. The percentage of surveyed organizations in the early adopters group is almost the same as that of technology camel model. Compared to the technology camel representing the surveyed individuals, we would consider the technology camel representing the organizations to look more like the camel proposed by Ghaffari and McNurlin, except it has two unbalanced humps, where the first one is $69 \%$ lower than the second one.

In summary, the TALC has shifted to the left and steepened for both individuals and organizations as a result of the increased rate of technology adoption over the years (see Figure 1).

\section{Comparison of Technology Adoption Pattern between Individuals and Organizations}

To test whether the percentage of the surveyed individuals in each group (eager beavers, early adopters, early majority, late majority and technology adverse) is the same as that of the organizations, a chi-square test was performed. The results disproved the hypothesis with a significance level less than .01 (see Table 3). Table 3 shows that $30 \%$ more individuals are in either the early adopter or the early majority groups, while $25 \%$ fewer of them are in either the late majority or the technically adverse groups. This may indicate that the individuals are ahead of the organizations in the adoption of new technology. It also may be explained by the characteristics of the respondents, who are all graduate students with half of them majoring in information systems. They should have a positive attitude toward and more appreciation of information technology, thus are more willing to become earlier adopters of new technology than the companies as a whole.

\section{Comparison of Technology Adoption Pattern between Males and Females}

Again, a chi-square test was used to test whether the percentage of the males in each group (eager beavers, early adopters, early majority, late majority and technology adverse) is the same as that of females. The results disproved the hypothesis with a significance level less than .05 (see Table 4). The results indicate that the pattern of technology adoption differs significantly between male and female. From Table 4 and Figure 3, it can be seen that males are more likely to adopt new technologies than are females. $3 \%$ and $15 \%$ more males put themselves in the eager beavers and the early adopters groups respectively than did females, while $11 \%$ fewer and $7 \%$ fewer males are in the early majority and the late majority groups respectively. 
Table 3. Technology Adoption Pattern between the Individuals and Organizations

\begin{tabular}{lccc} 
& \multicolumn{2}{c}{ Surveyed Organizations } & \multicolumn{2}{c}{ Surveyed Individuals } \\
\cline { 2 - 4 } Group & Actual Freq. & Actual Freq. & Expected Freq. \\
\hline Eager Beavers & $13(7.3 \%)$ & $6(3.2 \%)$ & $14(7.3 \%)$ \\
Early Adopters & $21(11.8 \%)$ & $32(17.2 \%)$ & $22(11.8 \%)$ \\
Early Majority & $52(29.2 \%)$ & $99(53.2 \%)$ & $54(29.2 \%)$ \\
Late Majority & $88(49.4 \%)$ & $49(26.3 \%)$ & $92(49.4 \%)$ \\
Technically Adverse & $4(2.2 \%)$ & $0(0.0 \%)$ & $4(2.2 \%)$ \\
Total & 178 & 186 & 178 \\
Chi-square Test & & $\chi^{2}=70.71, \mathrm{df}=4, \mathrm{P}<0.001$ &
\end{tabular}

Table 4. Technology Adoption Pattern between Males and Females

\begin{tabular}{lccc} 
& Male & \multicolumn{2}{c}{ Female } \\
\cline { 2 - 4 } Group & Actual Freq. & Actual Freq. & Expected Freq. \\
\hline Eager Beavers & $5(4.4 \%)$ & $1(1.4 \%)$ & $3(4.4 \%)$ \\
Early Adopters & $26(22.8 \%)$ & $6(8.3 \%)$ & $16(22.8 \%)$ \\
Early Majority & $56(49.1 \%)$ & $43(59.7 \%)$ & $35(49.1 \%)$ \\
Late Majority & $27(23.7 \%)$ & $22(30.6 \%)$ & $17(23.7 \%)$ \\
Technically Adverse & $0(0.0 \%)$ & $0(0.0 \%)$ & $0(0.0 \%)$ \\
Total & 114 & 72 & 72 \\
Chi-square Test & & $\chi^{2}=10.55, \mathrm{df}=4, \mathrm{P}<0.05$ &
\end{tabular}

This is not a surprising finding. The gender gap in the adoption of technology has received considerable attention in the literature. Many empirical studies have reported gender inequality in this area. For example, Reinen and Plomp [10] found that females knew less about information technology and enjoyed using it less than males. Shashaani and Khalili [11] found that females had low confidence in their own ability to work with computers even though they showed strong beliefs in equal gender ability and competence in use of computers. Liaw [4] found that males had more positive perceptions toward computers and web technologies. It is clear that special efforts need to be made in increasing the confidence and interest of females in the adoption of new technology.

\section{CONCLUSIONS}

The focus of this study was to investigate whether the pattern of the TALC in the shape of the technology camel has changed over the time and whether this pattern differs significantly between organizations and individuals, and between males and females. It was found that the adoption curve has shifted to the left, with fewer individuals/companies belonging to the technically adverse group. Moreover, the results showed that individuals are ahead of organizations in the adoption of new technologies and males are more willing to adopt new technologies than females. 
This study confirms the results of other research which indicates that the pattern of TALC is not the same for all the groups and may be dependent on other factors such as the type of the groups (individuals, companies, and industries) and gender. For example, Kambil et al. [5] found that senior management, the inclusion of technology in corporate strategy, and a firm's resources influence the corporate adoption of web technology.

\section{REFERENCES}

1. Au, A. K. \& Enderwick, P. (2000). A Cognitive Model Attitude towards Technology Adoption, Journal of Managerial Psychology, 15(4), 266-282.

2. Bass, F. M. (1969). A New Product Growth Model for Consumer Durables, Management Science, 15(5), 215-227.

3. Ghaffari, G. \& McNurlin, B. (July 1997). The Technology Camel. In Barbara C. McNurlin \& Ralph H Sprague, Jr. (Eds.), Information Systems Management in Practice (4th ed.), Prentice-Hall.

4. Liaw, S. S. (2002). An Internet Survey for Perceptions of Computers and The World Wide Web: Relationship, Predication, and Difference. Computers in Human Behavior, 18(1), 1735 .

5. Kambil, A., Kamis, A., Koufaris, M. \& Lucas H.C., Jr. (2000). Influence on the Corporate Adoption of Web technology, Communications of ACM, 43(11), 264-271.

6. Mahan, V., Muller, E. \& Bass, F. M. (1990). New Product Diffusion Models in Marketing: A Review and Directions for Research. Journal of Marketing, 54, 1-26.

7. Morahan-Martin, J. \& Schumacher, P. (1999). Comparison of Computer and Internet Competency, Experiences and Skills by Gender (Abstract), Proceedings of the Annual Meeting of the Society for Computers in Psychology, 1999, Los Angeles, CA.

8. Moore, G. A. (1991). Crossing the Chasm, New York: Harper Business.

9. Ray, C. M., Sormunen, C. \& Harris, T. M. (1999). Men's and Women's Attitudes Toward Computer Technology: A Comparison, Office System Research Journal, 17(1), 1.

10. Reinen, I. J. \& Plomp, T. (1993). Some Gender Issues in Educational Computer Use: Results of International Comparative Survey, Computers in Education, 20, 353-365.

11. Shashaani, L. \& Khalili, A. (2001). Gender and Computers: Similarities and Differences in Iranian College Students' Attitudes toward Computers, Computers and Educations, 37(3-4), 363-375. 